\title{
High-Speed BLDC Motor Design for Suction Fan and Impact on the Loss caused by Core Welding
}

\author{
Hyun-Seok Hong*, In-Gun Kim*, Ho-Joon Lee**, Sung-Chul Go*** and Ju Lee ${ }^{\dagger}$
}

\begin{abstract}
This paper deals with the effects of welding, which is done to fix the stator stack, on a motor in case of fabricating a prototype motor that is manufactured in a small quantity. In the case of a small motor, the stator is designed and fabricated with the segmented core as a way to raise the fill factor of winding wire to the utmost within a limited size. In case of fabrication by welding both inside and outside of the stator in order to fix the segmented-core stator, the effects of stack are ignored, and the eddy current loss occurs. This paper performed the no-load test on an IPM-type BLDC motor for driving the suction fan of a vacuum cleaner, which was manufactured by using a segmented-core stator. As a result of the test, it was found that input power more than expected was supplied. To analyze the effects of welding by using the finite element analysis method and verify them experimentally, a stator was re-manufactured by bonding, and input power supplied during the no-load test was compared.
\end{abstract}

Keywords: BLDC motor, Suction fan, Core welding, Loss

\section{Introduction}

The qualification of a motor manufactured for R\&D of better motors is a very important stage. Unlike motors having lines constructed for mass production, however, prototype motors created by R\&D are manufactured in small quantity. Therefore, the manufacture process of a prototype will be different from that of mass-produced motors. In the case of a prototype, welding is commonly used to fix laminated cores, given the characteristics of a motor manufactured as a structure made up of laminations of thin electric steel (hereinafter, "core"). In case of welding like this, however, the material of a welding rod and a welding area may influence the performance of a motor [1]. Particularly, for the stator which is designed in consideration of magnetic flux density saturation and in which most of core loss occurs, the influence of welding will be not a few [2-4].

The prototype motor developed from R\&D of this paper is an interior permanent magnet-type (hereinafter, "IPM") brushless direct current (hereinafter, "BLDC") motor designed to drive the load of a suction fan for a vacuum cleaner. It is a premium motor that is applied to the cordless vacuum cleaner and the robot vacuum cleaner, and was designed to have high efficiency and high output power density under the conditions of limited size and current density. In particular, the stator core was segmented

$\dagger$ Corresponding Author: Dept. of Electrical Engineering, Hanyang University, Korea. (julee@hanyang.ac.kr)

* Dept. of Electrical Engineering, Hanyang University, Korea. (hhs0321@gmail.com,waterkig@naver.com)

* Dept. of Electric Automatization, University of Busan Institute of Science and Technology, Korea. (hjlee@bist.ac.kr)

*** Dept. of Mechatronics R\&D Center. Mechatronics Group. Samsung Electronics Co., Ltd., Korea. (sc.go@samsung.com)

Received: March 4, 2016; Accepted: June 17, 2016 so that the fill factor might be raised to the utmost in order to reduce copper loss that arises in the winding wire. In general, the stator is manufactured in such a way that thin electrical steel having one side is laminated and that the outside of the stator is welded. In case of manufacturing a stator by using segmented electrical steel, however, both inside and outside of each joint portion are welded to make one stator [5]. The model developed from the R\&D of this paper was also fabricated in the same way. BLDC motors have gained popularity due to their high efficiency, compact form, reliability, and low maintenance $[6,7]$. As a result of a no-load test performed to verify the designed motor, it was found that non-ideally excessive input power was supplied. Compared with the 500 [W] output power at the rated rotating velocity of 80000 [rpm], the no-load test showed that the motor input power measured was $20 \%$ of the rated power, and thus it was found that a very high loss occurred. Various analyses were performed to detect the cause of the problem, and the finite element analysis method (hereinafter, "FEM") revealed core loss (eddy current loss) additionally arising from welding. To verify this by experiment, a secondary prototype was fabricated by using the bonding method, not welding the stator. The no-load test was performed with the primary prototype and the secondary prototype under the same environment, and the results of FEM analyses were comparatively verified by comparing electric energy inputted in the BLDC motor at each driving speed.

\section{Design of a High-speed BLDC Motor for Driving the Suction Fan of a Cleaner}

This chapter introduces general matters on calculating 
and designing the load of a high-speed BLDC motor for driving the suction fan. Section 2.1 contains the detailed calculation of load for the suction fan of a cleaner, and the required specification of the motor. Section 2.2 shows general matters on BLDC motor design for driving at $80,000[\mathrm{rpm}]$ and the results of finite element analysis.

\subsection{Calculation of fan load and the required specifi- cation}

Fig. 1 shows the speed-torque curve for motors by capacity according to the suction orifice diameter of a cleaner, and the load curve of a suction fan. The load of a vacuum cleaner varies with the kind and amount of object subjected to suction, and the cleanness of a suction orifice, that is, the size of suction orifice diameter. As seen from the load curve in Fig. 1, the larger the suction orifice diameter, the larger the load. Given that the BLDC motor outputs 345 [W], 500 [W] and 720 [W], points A, B, and C show torque characteristics by speed according to loads, respectively.

For example, point $\mathrm{C}$ may be understood as follows. For the motor to be able to rotate at over 100 thousand [rpm] near a suction orifice of 30 phi $(\Phi)$, which is close to full load, a torque of $80[\mathrm{mNm}]$ and above is required, in which case the output power is 720 [W] and above.

The vacuum cleaner of this study works most with a suction orifice diameter of $\Phi 11$. Therefore, the load at this time was calculated as the rated load, and the design was developed by focusing on the efficiency of the motor unit and the efficiency of the system, which includes the inverter and the fan, at the rated load. As for the capacity, DC voltage of 36 [V] (ten 3.6 [V] battery cells) was used,

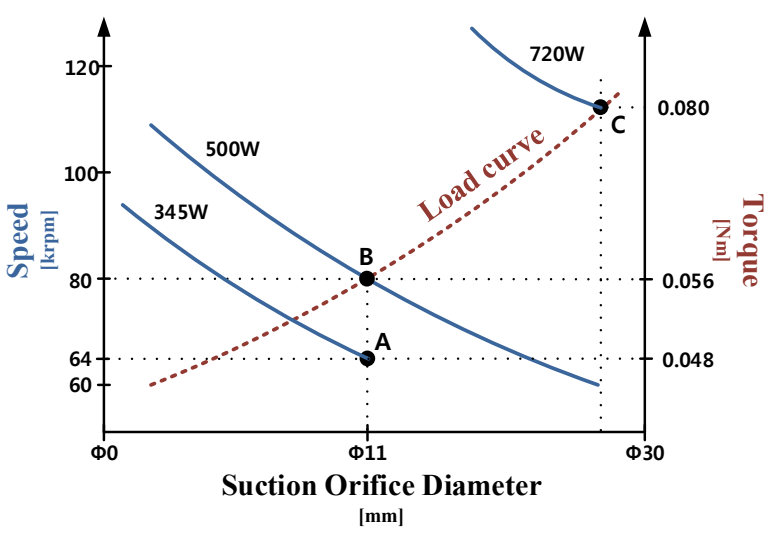

Fig. 1. Fan load curve of the suction orifice diameter

Table 1. Requirements specification of the motor

\begin{tabular}{c|c|c}
\hline Parameter & Value & Unit \\
\hline Required Torque & 56 & $\mathrm{mNm}$ \\
\hline Motor Efficiency(with Inverter) & 85 & $\%$ \\
\hline Rated Power & 500 & $\mathrm{~W}$ \\
\hline Rated Rotating Speed & 80,000 & $\mathrm{rpm}$ \\
\hline DC Voltage & 36 & $\mathrm{~V}$ \\
\hline
\end{tabular}

and $500[\mathrm{~W}]$ was selected so that higher output than the existing one might be obtained. Therefore, the BLDC motor was designed with point $\mathrm{B}$.

Table 1 shows the required specification and voltage limit of the motor. The rated voltage specification of a battery that can be used under the limit conditions is 36 [V] as mentioned above; and owing to the limitations in the internal size of a vacuum cleaner, the design of the motor was developed with its external diameter of $43[\mathrm{~mm}]$ and below and its shaft axial length of $20[\mathrm{~mm}]$ and below.

\subsection{Motor design and the FEM analysis}

Fig. 2 shows the designing sequence of the BLDC motor. The load characteristics, the design points, and the voltage limit were mentioned above, and so are omitted. As for the current limit, the design was performed, considering the number and diameters of winding wires lest the current density exceed $5\left[\mathrm{~A}_{\mathrm{rms}} / \mathrm{mm}^{2}\right]$. As it rotates at the speed of 80,000 [rpm], an IPM structure that can prevent permanent magnet scattering was selected as the type of the motor. As for the pole number, although more poles can increase power density, the 4-pole was selected for driving at 80,000 [rpm], considering the controllability of switching frequency, etc. In the design flow, magnetic loading and electric loading were properly used to minimize the size, and materials were also selected so that they might be able to meet the driving temperature and the required output power. For the permanent magnet, N38UH of $\mathrm{Nd}$ series was used; and for the core, the material of 20PN1500 (based on POSCO company) with the thickness of 0.2 [T] was used.

Fig. 3 shows the structure of the motor designed according to the above designing sequence. The windings are wrapped in 6 slots as teeth concentrated windings, and there is the stator overhang structure at the opposite side of load. In general, the stator overhang structure is used to increase the power density within a limited size, by increasing the use amount of permanent magnet. In the case of this motor, however, it is intended to raise the stability of control during high-speed driving by detecting more correctly the location of a rotator for BLDC control.

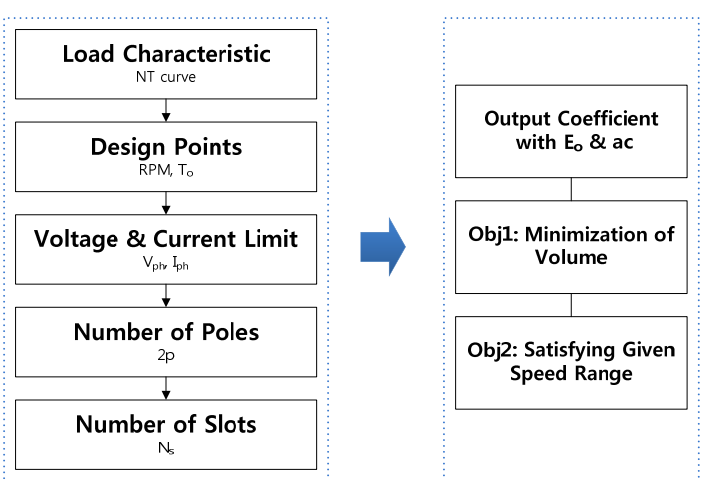

Fig. 2. Design flow of BLDC motor 

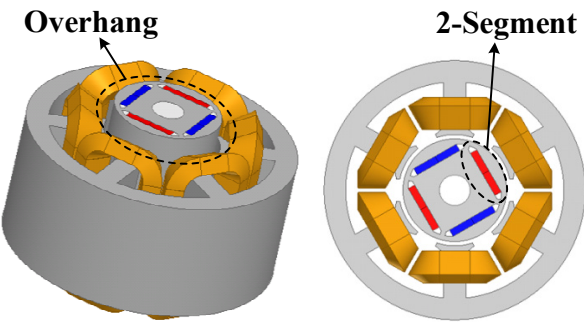

Fig. 3. Structure of BLDC motor

Table 2. Demension of parts

\begin{tabular}{c|c|c|c}
\hline Part & Parameter & Value & Unit \\
\hline \multirow{4}{*}{ Stator } & Stator Outer Diameter & 42.65 & $\mathrm{~mm}$ \\
\cline { 2 - 4 } & Stator Yoke & 3.5 & $\mathrm{~mm}$ \\
\cline { 2 - 4 } & Teeth Width & 3.6744 & $\mathrm{~mm}$ \\
\cline { 2 - 4 } & Web Width & 0.8 & $\mathrm{~mm}$ \\
\cline { 2 - 4 } & Slot Opening & 3.65 & $\mathrm{~mm}$ \\
\hline \multirow{3}{*}{ Rotor } & Rotor Diameter & 16.9 & $\mathrm{~mm}$ \\
\cline { 2 - 4 } & Magnet Size & $8.25 / 1.2$ & $\mathrm{~mm}$ \\
\cline { 2 - 4 } & Shaft Diameter & 5 & $\mathrm{~mm}$ \\
\hline & Air-gap & 0.8 & $\mathrm{~mm}$ \\
\hline
\end{tabular}

To consider the effects of permanent magnet and core lengthened by overhang, 2D analysis and 3D analysis were carried out together, using the finite element analysis method. The 2D analysis with a small number of finite elements can be used for a basic design that meets the requirements of the motor within a limited size, but fails to consider the structure of overhang to detect the position of the rotator and the effects of winding wire end-turn. Therefore, as shown in Fig. 3, the 3D model was modeled on the basis of a 2D basic model, and analysis was performed in consideration of the structure of rotator overhang and the end-turn effects of stator winding wire $[8,9]$.

The permanent magnet was designed to be of the twosegment structure. As it rotates at the speed of 80,000 [rpm], permanent magnet loss caused inside the permanent magnet has not a few effects in the 500 [W] motor. Therefore, for designing a motor of better performance, the design was carried out with dividing the permanent magnet into two segments, as shown in Fig. 3.

The dimensions of a BLDC motor designed thus are presented in Table 2 below.

Fig. 4 shows an external circuit linked for the BLDC motor periodic model and analysis. The BLDC motor rotates by the jumping magnetic field caused by two-phase $120^{\circ}$ commutation, not by the rotating magnetic field caused by three-phase $180^{\circ}$ commutation. Therefore, voltage generator analysis, not current generator analysis that applies three-phase sinusoidal alternating current to each phase, should be performed in linkage to an external circuit.

As a result of analysis at the rated rotating velocity of 80,000 [rpm], the design point, it was possible to obtain back electromotive force, torque, loss, and input phasecurrent waveform, as shown in Fig. 5 below.

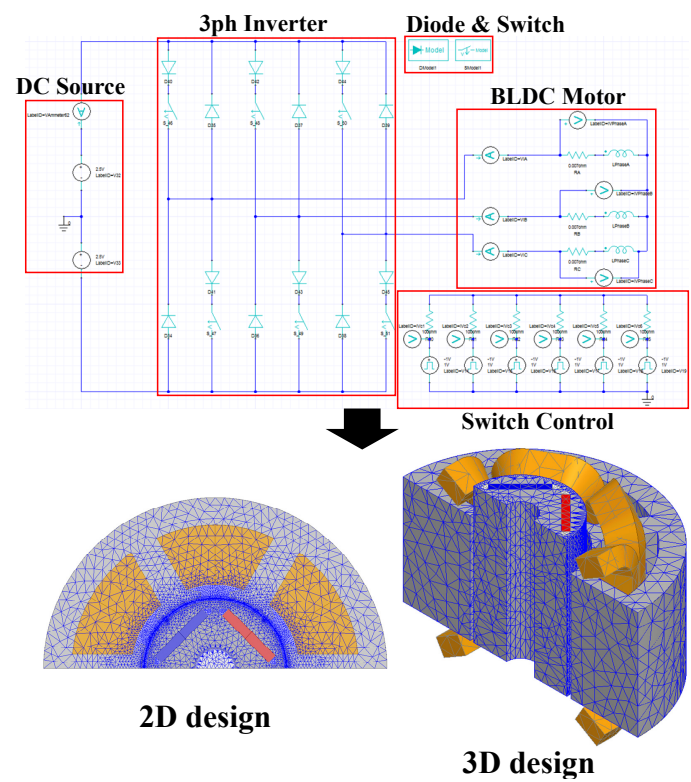

Fig. 4. FEM Analysis by using external control circuit
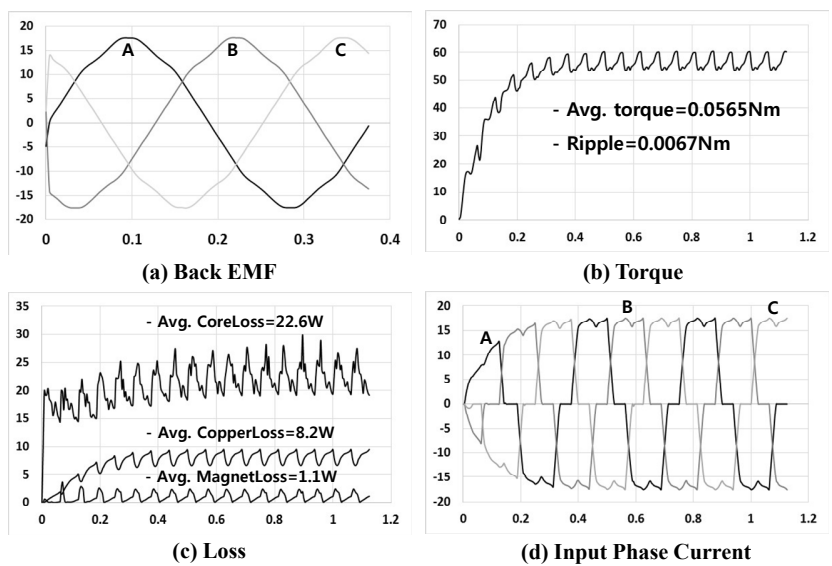

Fig. 5. FEM Results of designed motor

First, it was checked whether the back-EMP waveform was sinusoidal in simulation under no-load condition. While generally the BLDC motor is designed for trapezoidal back electromotive force, IPM-type structure, which can prevent permanent magnet scattering, is essential, given the characteristics of the motor that drives at high velocity. Therefore, the waveform of back electromotive force becomes sinusoidal irrespective of the magnetization direction of a permanent magnet. Then, it was confirmed that a torque value satisfying the required torque came out in the simulation under no-load condition, and the motor efficiency was calculated using air-gap power, core loss, permanent magnet loss, and copper loss.

The cause for ripple arising in the torque waveform and the loss waveform can be explained by the ripple of input phase-current waveform. In general, the rise time of current is shorter than the fall time due to the inductance element of winding wire, and thus input current may be missing as much as the difference. In addition, in case of driving at 
high speed as in the designed BLDC motor, the inductance element decreases due to increased heat, and the time constant increases in proportion to the decrease in inductance; and thus the stretching of current becomes severer than at the region of low speed. For this reason, the element of ripple occurs at the input phase current, and the generated ripple element of current also causes ripple elements in torque and loss [10-14].

The designed motor achieved the target values of torque and efficiency, with $56.5[\mathrm{mNm}]$ and $93.4[\%]$, respectively.

\section{Verification by experiment}

Section 3.1 shows the structure of the fabricated primary prototype motor and the results of no-load test. And Section 3.2 analyzed the problem of stator welding, using the finite element analysis method; and fabricated the secondary prototype motor by bonding, not welding, for the verification of experiment, and performed a no-load test in the same way as in the primary prototype. The results of no-load tests on the primary prototype and the secondary prototype were compared; and the effects of stator welding on the motor were verified.

\subsection{The $1^{\text {st }}$ prototype manufactured through welding}

Fig. 6 (a) and (b) shows the stator core fabricated in segmentation and welded for fixing in case of fabricating the primary prototype.

Fig. 7 shows a primary prototype finished in this process.

As a result of designing smaller slot openings so as to reduce output ripple, it was inevitable to manufacture the prototype with the segmental cores of the stator. Thus, the

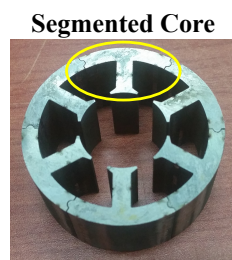

(a)

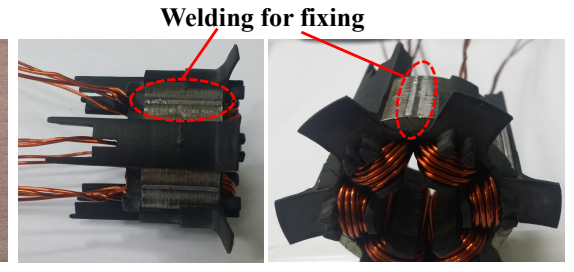

(b)
Fig. 6. Stator produced for welding

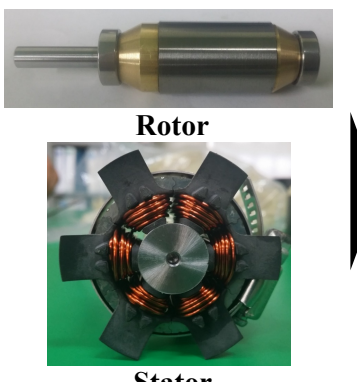

Stator

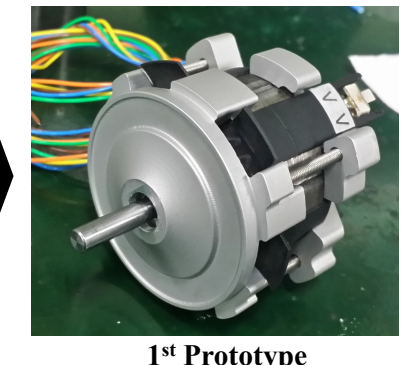

$1^{\text {st }}$ Prototype
Fig. 7. Primary prototype prototype was manufactured with six segmental cores, the same number as the number of slots. In addition, as for the welded zone, a total of 30 areas including 12 internal areas of the stator and 18 external areas of the stator were welded. The amount of core loss increases as much as high frequency, as in Equation (1), because it is a motor rotating at a high speed, and thus thin and expensive electric steel was used. And welding was employed in many areas to fix the segmented core.

$$
P_{i}=P_{h}+P_{e}=k_{h} f B_{m}^{n}+k_{e} f^{2} B_{m}^{2} \quad\left[\mathrm{~W} / \mathrm{m}^{3}\right]
$$

Result of comparison analysis waveform and experimental waveform of the back electromotive force for design verification production model, as shown in Fig. 8, it can be seen that substantially coincide. Back electromotive force was measured at a rotational speed of 1090 [rpm], the ripple waveform caused by noise is the experiment waveform.

As a result of performing the no-load test, as shown in Fig. 9, to verify the manufacturability of the primary prototype, it was found that the inverter output power increased greatly as speed increased, as shown in Table 3.

The inverter output power is the same as the motor input. Ideally, there is no motor input in case of no load; for the motor to rotate actually, however, torque should

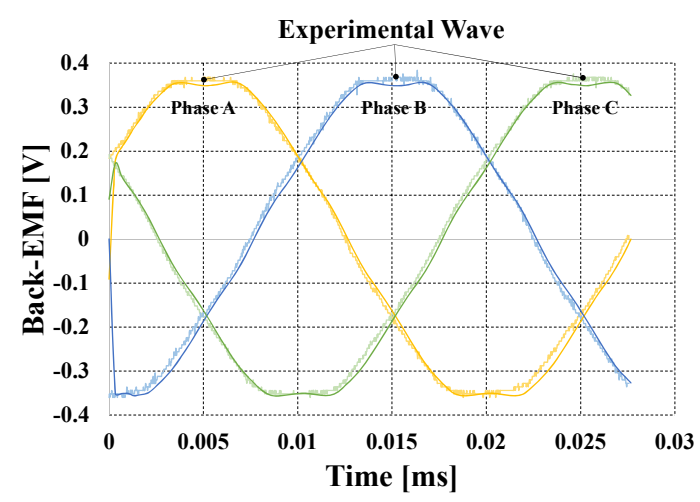

Fig. 8. Back-EMF wave (@1090 [rpm])

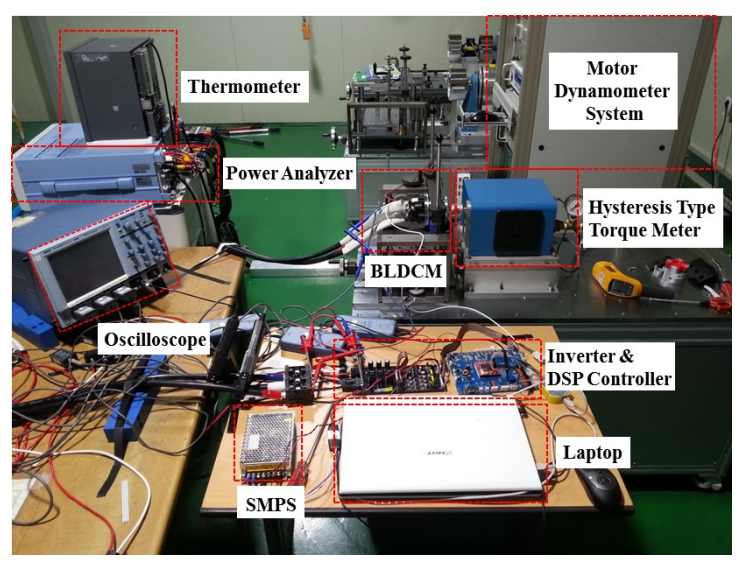

Fig. 9. No-Load test 
Table 3. No-Load test results of the $1^{\text {st }}$ prototype

\begin{tabular}{c|c|c|c}
\hline $\begin{array}{c}\text { Rotating Speed } \\
{[\mathrm{rpm}]}\end{array}$ & $\begin{array}{c}\text { DC Voltage } \\
{[\mathrm{V}]}\end{array}$ & $\begin{array}{c}\text { DC Current } \\
{[\mathrm{A}]}\end{array}$ & $\begin{array}{c}\text { DC Input Power } \\
{[\mathrm{W}]}\end{array}$ \\
\hline 10000 & 35.949 & 0.2737 & 9.39 \\
\hline 20000 & 35.946 & 0.4751 & 16.89 \\
\hline 30000 & 35.941 & 0.7472 & 26.54 \\
\hline 40000 & 35.936 & 1.1162 & 39.34 \\
\hline 50000 & 35.928 & 1.5702 & 55.99 \\
\hline 60000 & 35.916 & 2.086 & 74.5 \\
\hline 70000 & 35.907 & 2.5435 & 90.09 \\
\hline 80000 & 35.897 & 3.0864 & 110.47 \\
\hline
\end{tabular}
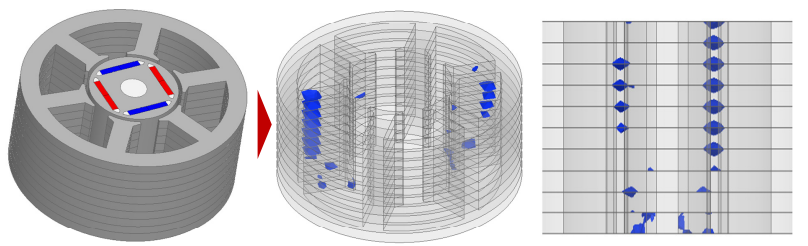

(a)

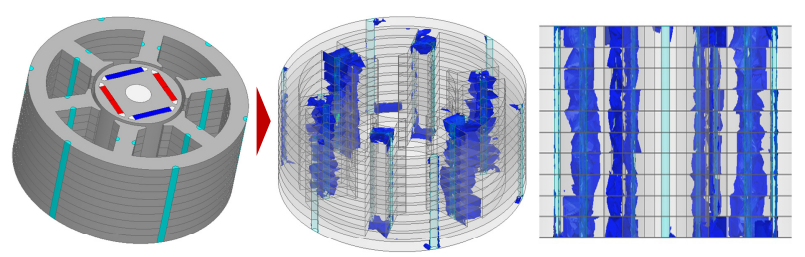

(b)

Fig. 10. Current density distribution (@80,000rpm): (a) Non-welding; (b) Welding

be produced to overcome the weight of the rotator, mechanical friction force, the stator structure having saliency, and the cogging force caused by the permanent magnet of the rotator. Therefore, in case of rotating only the motor without fastening it to a dynamo system, electric power should be supplied to the motor. However, it is seen that electric energy provided to the motor according to speeds becomes very large compared with the capacity of the designed motor.

\subsection{The $2^{\text {nd }}$ prototype and experiment}

As seen in Table 3, during the no-load test of the 500 [W] small BLDC motor, approximately 110 [W] of DC input was measured at the 80,000 [rpm] of rated rotating speed. This means that loss caused in the motor is 110 [W]. Although there may actually be external loss not considered during design (bearing friction loss, rotor wind loss, etc.), it is problematic that loss exceeding $1 / 5$ of rated power occurs. Therefore, to find out the cause of the problem, the difference between the design model and the fabrication model was investigated. It was found that the most significant one among fabrication conditions not reflected in the design model was welding on the stator.

As for the method of simulation, a 3D model was designed so that the effects of welding might be observed
Table 4. FEM analysis and measurement values of No-load (@80,000rpm)

\begin{tabular}{c|c|c|c}
\hline \multirow{2}{*}{$\begin{array}{c}\text { FEM Analysis } \\
\text { Value }\end{array}$} & $\begin{array}{c}\text { Welding } \\
\text { Condition }\end{array}$ & $\begin{array}{c}\text { Loss } \\
{[\mathrm{W}]}\end{array}$ & $\begin{array}{c}\text { Rate of Increase } \\
{[\%]}\end{array}$ \\
\cline { 2 - 3 } & $\mathrm{X}$ & 16.29 & \multirow{2}{*}{250} \\
\hline \multirow{2}{*}{$\begin{array}{c}\text { Measurement } \\
\text { Value }\end{array}$} & $\mathrm{O}$ & 57.02 & \multirow{2}{*}{315} \\
\cline { 2 - 3 } & $\begin{array}{c}\mathrm{X} \\
\left(1^{\text {st }} \text { prototype }\right)\end{array}$ & 26.65 & \multirow{2}{*}{315} \\
\cline { 2 - 3 }$\left(2^{\text {nd }}\right.$ prototype $)$ & 110.47 & \\
\hline
\end{tabular}

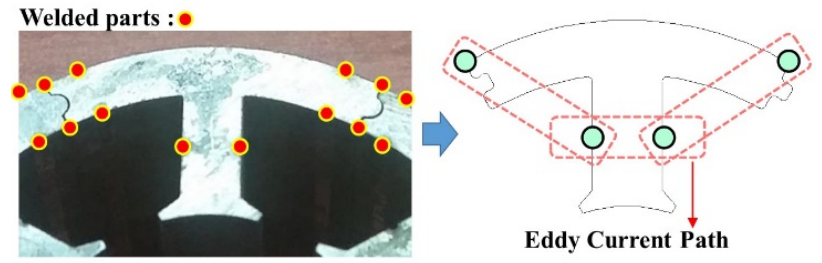

Fig. 11. Eddy current path by stator welding

in a simplified way.

As shown in Fig. 10, $\mathrm{Pb}$ (plumbum) material was applied to the welding zone, and the electrical steel was modeled by dividing the height of its stack into 10 . In case of modeling with dozens of thin electric steel as in the actual fabrication model, the difficulty lies in the analysis because the number of elements for the finite element analysis increases greatly. Therefore, the effects of welding were identified by 3D FEM analysis in terms of whether current density caused by welding occurred or not. This was not a problem because this study aimed to investigate the effects of welding, and the analysis was performed with a simplified model setting the rotator speed to 80,000 [rpm].

As a result, it was found that current density was distributed in the direction of lamination along the welding zone, as shown in Fig. 10 (b). This means that a magnetic closed-loop was formed in the shaft axial direction, and thus eddy current loss occurred.

Though in a simplified way, Table 4 shows the numerical increase. Owing to difference from actual test conditions, however, the analysis value and the measurement value are different, but their tendency is the same.

The magnetic closed-loop is formed due to the welding zone, as shown in Fig. 11. Therefore, this eddy current path increases eddy current loss and reduces the core stack effects, which results in the performance degradation of the motor.

As shown in Eq. (1), the core loss is separated into the hysteresis loss and the eddy current loss. And it is usually proportional to the frequency of magnetic field provided from the outside, and is in proportion to the square of flux density $[15,16]$. Moreover, in the case of a small BLDC motor driven at high speed, the share of core loss caused by welding is great, for the frequency is very high and the flux density caused by $\mathrm{Nd}$ (Neodymium) permanent 
magnet is also high.

To verify the analysis of FEM and the results of no-load test on the primary prototype, the secondary prototype was fabricated by using bonding with no welding. The secondary prototype motor manufactured was subjected to the same no-load test as for the primary prototype motor.

As shown in Table 5 and Fig. 12, DC input applied to drive the secondary prototype motor at the speed of 80,000 [rpm] was measured to be 26.65 [W], very low compared with the primary prototype. This represents the reduction of $75 \%$ in input power into the motor, that is, loss, compared with the primary prototype motor. The interaction between the magnetic field flux of the rotator and the magnetic closed-loop artificially formed by stator welding creates eddy current loss. The results of the above experiment show that this phenomenon has very great effects on a high-speed rotary machine of high rotator frequency.

For the verification of the performance of the secondary prototype motor fabricated without welding, Table 6 shows the results of SET test and the results of FEM at the rated load. The reasons that error occurred in the results of the

Table 5. No-Load test results of the $1^{\text {st }}$ prototype

\begin{tabular}{c|c|c|c}
\hline $\begin{array}{c}\text { Rotating Speed } \\
{[\mathrm{rpm}]}\end{array}$ & $\begin{array}{c}\text { DC Voltage } \\
{[\mathrm{V}]}\end{array}$ & $\begin{array}{c}\text { DC Current } \\
{[\mathrm{A}]}\end{array}$ & $\begin{array}{c}\text { DC Input Power } \\
{[\mathrm{W}]}\end{array}$ \\
\hline 10000 & 35.946 & 0.195 & 6.73 \\
\hline 20000 & 35.942 & 0.261 & 9.25 \\
\hline 30000 & 35.939 & 0.327 & 11.73 \\
\hline 40000 & 35.940 & 0.362 & 13.00 \\
\hline 50000 & 35.941 & 0.447 & 16.06 \\
\hline 60000 & 35.940 & 0.524 & 18.82 \\
\hline 70000 & 35.941 & 0.615 & 22.09 \\
\hline 80000 & 35.934 & 0.743 & 26.65 \\
\hline
\end{tabular}

Table 6. FEM(up) and Set-test(down) values of the $2^{\text {nd }}$ prototype in rated-load (@80,000rpm)

\begin{tabular}{c|c|c|c|c|c}
\hline $\begin{array}{c}\text { Torque } \\
{[\mathrm{Nm}]}\end{array}$ & $\begin{array}{c}\text { Air-gap Power } \\
{[\mathrm{W}]}\end{array}$ & $\begin{array}{c}\text { Copper Loss } \\
{[\mathrm{W}]}\end{array}$ & $\begin{array}{c}\text { Core Loss } \\
{[\mathrm{W}]}\end{array}$ & $\begin{array}{c}\text { Motor Effi. } \\
{[\%]}\end{array}$ \\
\hline 35.946 & 473.33 & 0.195 & 6.73 & 93.37 \\
\hline \multicolumn{6}{|c}{} \\
\hline $\begin{array}{c}\text { Input } \\
\text { Power [W] }\end{array}$ & $\begin{array}{c}\text { Suction } \\
\text { Power [W] }\end{array}$ & $\begin{array}{c}\text { System } \\
\text { Effi. [\%] }\end{array}$ & $\begin{array}{c}\text { Fan } \\
\text { Effi. [\%] }\end{array}$ & $\begin{array}{c}\text { Inv. } \\
\text { Effi. [\%] }\end{array}$ & $\begin{array}{c}\text { Motor } \\
\text { Effi. [\%] }\end{array}$ \\
\hline 470.58 & 250.69 & 53.0 & 60.0 & 95.4 & 92.59 \\
\hline
\end{tabular}

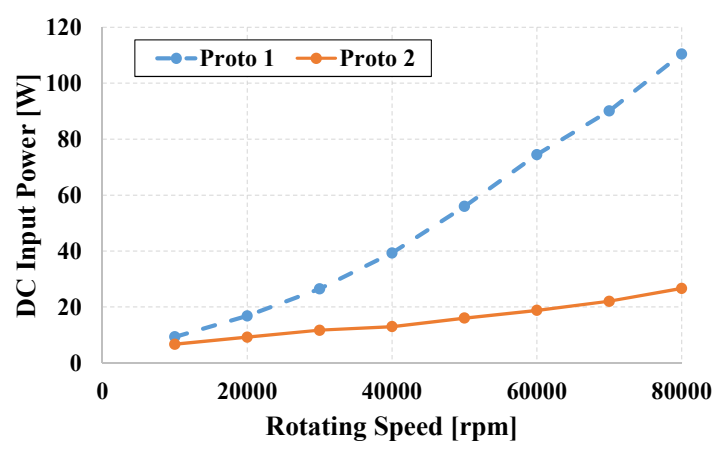

Fig. 12. Comparison of DC input power actual test are manufacturability and the effects of mechanical loss under actual driving conditions. For the 500 [W] small motor, the results of Table 6 show a sufficient level for verification regarding the design.

\section{Conclusion}

This paper verified the problem, which may arise in the design of 500 [W] BLDC motor for driving a suction fan and in the prototype motor manufactured in a small quantity, by FEM analysis and experiments with fabrication models.

There is always a problem that may arise from an $R \& D$ model, which has no production line because a small quantity is manufactured unlike mass production-type models. Such a lowered manufacturability is not equal to drawing out all performance of the design model.

The small BLDC motor dealt with by this study also showed the problem of the misuse of welding on the stator due to a small size, thin electric steel, and segmented stator coil. Welding on the inside and outside of the stator formed a magnetic closed-loop, which resulted in very great core loss. Attention should be given lest not only the BLDC motor but also all electric machinery and apparatuses fabricated according to electromagnetic principles cause such a problem.

This study verifies and proposes from the FEM analysis and the results of experiment that in case of fabricating a motor, the welding zone should be selected lest a magnetic closed-loop be formed.

\section{Acknowledgements}

This work was supported by the Human Resources Program in Energy Technology of the Korea Institute of Energy Technology Evaluation and Planning (KETEP), granted financial resource from the Ministry of Trade, Industry \& Energy, Republic of Korea. (No. 2015 4030200900).

This work was supported in part by the Basic Science Research Program through the NRF, Ministry of Education under Grant 2013R1A1A2062104.

\section{References}

[1] Alexander J. Clerc, Annette Muetze, "Measurement of Stator Core Magnetic Degradation During the Manufacturing Process," Transactions on Industry Applications, IEEE, vol. 48, No. 4, pp. 1344-1352, July/August. 2012.

[2] Udaya K. Madawala, John T.Boys, "Magnetic Field Analysis of an Ironless Brushless DC Machine," Magnetics IEEE Transactions on, vol. 41, No. 8, pp. 2384-2390, August. 2005. 
[3] C. I. McClay and S. Williamson, "The variation of cage motor losses with skew," IEEE Trans. Ind. Appl., vol. 36, no. 6, pp. 1563-1570, Nov./Dec. 2000.

[4] A. Cassat, C. Espanet, and N. Wavre, "BLDC motor stator and rotor iron losses and thermal behavior based on lumped schemes and 3-D FEM analysis," IEEE Trans. Ind. Appl., vol. 39, no. 5, pp. 1314-1322, Sep./Oct. 2003.

[5] Andreas Krings, Shafigh Nategh, Oskar Wallmark, and Juliette Soulard, "Influence of the Welding Process on the Performance of Slotless PM Motors With SiFe and NiFe Stator Laminations," in Proc. IEEE Trans. Ind. Appl., vol. 50, no. 1, pp. 296-306, Jan./Feb. 2014.

[6] T.-H. Kim, H.-W. Lee, and M. Ehsani, "Advanced sensorless drive technique for multiphase BLDC motors," in Proc. IEEE IECON, 2004, vol. 1, pp. 926-931.

[7] A. Darba, F. De Belie, and J. Melkebeek, "Sensorless commutation and speed control of brushless dcmachine drives based on the back-EMF symmetric threshold-tracking," in Proc. IEEE IEMDC, May 2013, pp. 492-497.

[8] K. C. Kim and J. Lee, "The dynamic analysis of a spoke-type permanent magnet generator with large overhang," IEEE Trans. Magn., vol. 41, no. 10, pp. 3805-3808, Oct. 2005.

[9] K. C. Kim, D. H. Koo, and J. Lee, "The study on the overhang coefficient for permanent magnet machine by experiment design method," IEEE Trans. Magn., vol. 43, no. 4, pp. 1833-1836, Apr. 2006.

[10] Chun-Lung Chiu, Yie-Tone Chen, You-Len Liang, and Ruey-Hsun Liang, "Optimal Driving Efficiency Design for the Single-Phase Brushless DC Fan Motor," IEEE Trans. Magn., vol. 46, no. 4, pp. 11231130, Apr. 2010.

[11] H. K. Samitha Ransara and Udaya K., "A Torque Ripple Compensation Technique for a Low-Cost Brushless DC Motor Drive," IEEE Trans. Ind. Electron., vol. 62, no. 10, pp. 6171-6182, Oct. 2015.

[12] Z. Zhu, L. Wu, and M. M. Jamil, "Distortion of backEMF and torque of PM brushless machines due to eccentricity," IEEE Trans. Magn., vol. 49, no. 8, pp. 4927-4936, Aug. 2013.

[13] R. Carlson, A. A. Tavares, J. P. Bastos, and M. LajoieMazenc, "Torque ripple attenuation in permanent magnet synchronous motors," in Conf. Rec. IEEE IAS Annu. Meeting, Oct. 1989, vol. 1, pp. 57-62.

[14] T. R. England, "Unique surface-wound brushless servo with improved torque ripple characteristics," IEEE Trans. Ind. Appl., vol. 24, no. 6, pp. 972-977, Nov./Dec. 1988.

[15] E. Dlala and A. Arkkio, "A general model for investigating the effects of the frequency converter on the magnetic iron losses of a squirrel-cage induction motor," IEEE Trans. Magn., vol. 45, no. 9, pp. 3303-3315, Sep. 2009.

[16] Z. Gmyrek, A. Boglietti, and A. Cavagnino, "Estimation of iron losses in induction motors: Calculation method, results and analysis," IEEE Trans. Ind. Electron., vol. 57, no. 1, pp. 161-171, Jan. 2010.

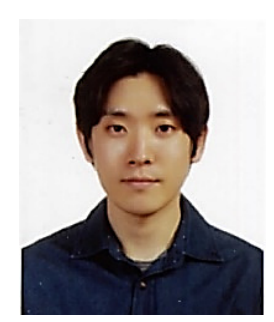

Hyun-Seok Hong He received his B.S. degree in Electrical Engineering from Dankook University, Seoul, Korea in 2012 and M.S. degree in Electrical Engineering from Hanyang University, Seoul, Korea in 2014. Since 2014, he has been pursuing the Ph.D. degree at the Department of Electrical Engineering, Hanyang University. His research interests include design, analysis, testing and control of motor/generator; power conversion systems; and applications of motor drive.

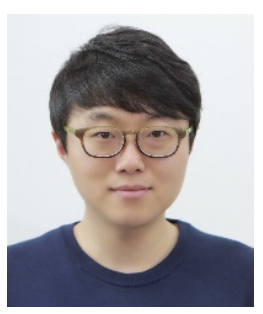

In-Gun Kim He received his B.S. degree in Electrical Engineering from Incheon University, Incheon, Korea in 2011, and his M.S. degree in Electrical Engineering from Hanyang University, Seoul, Korea in 2013. Since 2013, he has been pursuing the Ph.D. degree at the Department of Electrical Engineering, Hanyang University. His research interests include design, analysis, testing and control of motor/generator; power conversion systems; and applications of motor drive, such as electric vehicles.

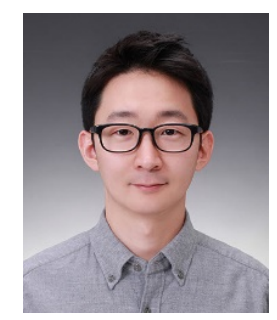

Ho-Joon Lee He received his M.S. and $\mathrm{PhD}$. degrees in Electrical Engineering from Hanyang University, Seoul, Korea in 2011 and 2015, respectively. He is currently a full-time lecturer of the Department of Electric Automatization Engineering at Busan Institute of Science and Technology University since 2015. His research interests include design, analysis, testing and control systems such as electric vehicles; and applications of spherical motor for robots.

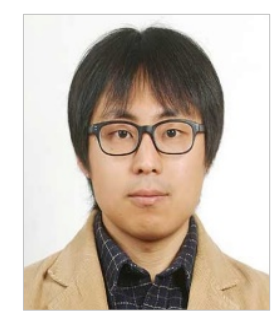

Sung-Chul Go He received his B.S., M.S. and Ph.D. degrees in Electrical Engineering from Hanyang University, Seoul, Korea in 2004, 2006 and 2010, respectively. $\mathrm{He}$ is now working in Samsung Electronics Co. His research interests include design, analysis, testing and control of motor/generator; 
power conversion systems; and applications of motor drive, such as electric vehicles, high-speed maglev train and renewable energy systems.

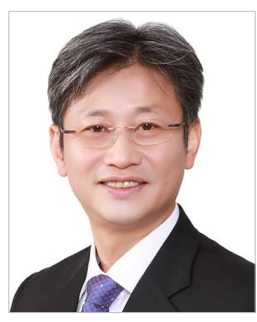

Ju Lee He received his M.S. degree from Hanyang University, Seoul, South Korea, in 1988, and his Ph.D. from Kyusyu University, Japan in 1997, both in Electrical Engineering, He joined Hanyang University in September, 1997 and is currently a Professor of the Division of Electrical and Biomedical Engineering. His main research interests include electric machinery and its drives, electromagnetic field analysis, new transformation systems such as hybrid electric vehicles (HEV), and high-speed electric trains and standardization. He is a member of the IEEE Industry Applications Society, Magnetics Society, and Power Electronics Society. 